\title{
IN-SITU OBSERVATIONS OF POINT-DEFECT PRECIPITATION AT DISLOCATIONS IN ELECTRON-IRRADIATED SILVER*
}

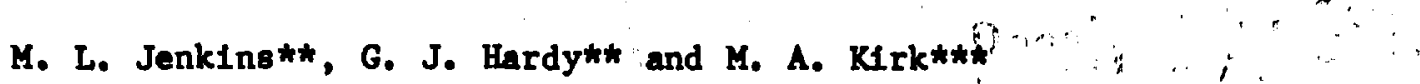 \\ **Department of Metallurgy and Sclence of Materlals \\ Univeraity of Oxford, Parks Road, Oxford OX1 3PH, England \\ ***Materials Sclence Division \\ Argoune National Laboratory, Argonne, IL 60439 U.S.A.
}

CONF-860953--12

DE87 004651

September 1986

\begin{abstract}
The submitted menueript hen been suthored by a contrector of the U.S. Government under contract No. W-31-100-EitG-38. Accordinoly, the U.S. Govermment retains a Accordinoly, the U. S. Gowermment retains a or reproduce the publimed form of this contribution, or allow others to do 10 , for U. S. Gowernment purposs.
\end{abstract}

\section{DISCLAIMER}

\begin{abstract}
This report was prepared as an account of work sponsored by an agency of the United States Governinent. Neither the United State Government nor any agency thereor, nor any of their employees, makes any warranty, express or implied, or assumes any legal lisbility or responeibility for the accuracy, completeness, or usefulness of any information; apparatus, product, or process discloeed, or represents that its use would not infringe privately owned rights. Reference herein to any specific commercial product, process, or service by trade name, trademart, manufacturer, or otherwise does not necessarily constitute or imply its endorement, recommendation, or favoring by the United States Government or any agency thereof. The views and opinions of authors expressed berein do not necessarily state or reflect those of the United Statea Government or any agency thereof.
\end{abstract}

Submitted to the International Conference on Vacancies and Interstitials in Metals and Alloys, Sept. 14-19, 1986, Berlin.

*Work supported in part by the U. S. Department of Energy, BES-Materials Sclences, under Contract W-31-109-Eng-38. 


\section{IN-SITU OBSERVATIONS OF POINT-DEFECT PRECIPITATION}

AT DISLOCATIONS IN ELECTRON-IRRADIATED SILVER

M L Jenkins, G J Hardy and M A Kirk+

Department of Metallurgy \& Science of Materials, University of Oxford, Parks Road, Oxford OX13PH

+Materials Science \& Technology Division, Argonne National Laboratory

\section{ABSTRACT}

In-situ weak-beam observations of the development of electron irradiation damage at dislocations in silver are described. Dislocations constrict and promote in their vicinity the formation of stacking-fault tetrahedra. The possibility that these are of interstitial nature is discussed.

\section{INTRODUCTION}

The climb of dissociated dislocations under high supersaturations of point defects has been studied experimentally at oxford for several years. In $\mathrm{Cu}-\mathrm{Al}$ alloys experiments carried out under interstitial supersaturations generated by irradiation $[1,2]$ and vacancy supersaturations due to quenching[3] have demonstrated that climb can proceed by loop nucleation on the individual partial dislocations. Subsequent interactions between these loops and both partials lead to complex configurations. Similar climb mechanisms have been shown to operate in Si[4] and GaAs[5]. In silver, however, where the partial separations are similar to the CuiosAl alloy of reference[2], dislocation loops do not appear to nucleate directly on the individual partial dislocations. Under room-temperature electron-irradiation dislocations in silver were observed to constrict and promote in their vicinity the formation of small stacking-fault tetrahedra (SFT) and dislocation loops. There was no indication of major dislocation climb nor of complex interactions between the elusters and line dislocations. There was some evidence that some SFT lay in the dilatational parts of the strain rields[2]. 
The nature of the small SFT rormed near dislocation Iines has been Investigated using the ' $2 \mathrm{kD}$ ' technlque, which makes use of displacements in dark-fleld diffraction contrast images produced by defocusing of the objective lens. This technique has been shown to be sulted to determining the nature of small SFT[6]. The experiments are described in detail in reference[7].. In summary, there was evidence that these small SFT formed near dislocations in electron-irradiated silver are of interstitial type. This is the rirst identificiation of interstitial SFT in any materlal. There are however some difficulties in applying the $121 / 2 D$ ' technique successfully and these have now led us to question the validity of this result (see the discussion section below).

The high-resolution in-situ experiments described here were intended to follow the development of damage at dislocation lines as a function of electron dose. It was hoped thereby to gain insight into the mechanisms operating and to help distinguish between the interstitial and vacancy models.

\section{EXPERIMENTAL DETAILS}

The in-situ experiments were carried out as follows. $3 \mathrm{~mm}$ discs of pure silver, cut parallel to a $\mid 111\}$ glide plane, were lightly deformed by bending and electro-polished to electron transparency using standard techniques. They were examined in the Argonne Kratos EM7 HVEM operating at 300KV, below the threshold for electron irradiation damage in silver, and long, isolated dislocations 1 ying in regions of foll of thickness $-100 \mathrm{~nm}$ were selected and characterized by weak-beam imaging. The voltage was then increased to IMV and the chosen dislocations were electron-irradiated with a fully-condensed beam for periods of a few seconds to a few minutes. A typical electron flux was $-2.10^{23}$ electrons $\mathrm{m}^{-2} \mathrm{~s}^{-1}$ giving a damage rate of -0.01 displacements $a^{-1} \mathrm{~min}^{-1}$. The voltage was then reduced to $300 \mathrm{kV}$ again, and the dislocation reanalysed using weak-beam imaging in various $[2 \overline{2} 0]$ and [111] reflections. The deviation parameter was typically $\mathrm{s}_{\mathrm{g}}=1 \cdot 1 \cdot 10^{-1} \mathrm{~nm}^{-1}$, corresponding to $(\mathrm{g}, 8 \mathrm{~g})$ conditions for $\mathrm{g}=11 \overline{1}$. The process was then repeated for the next irradiation step. In the experiment described below nine irradiation steps were completed, with a final total electron irradiation time of 13 mins.

\section{RESULTS}

A room-temperature irradiation experiment is illustrated in figures 1-3. Figure 1(a) shows a dislocation imaged prior to irradiation in a reflection $g=2 \overline{2} 0$ for which $\mid g \cdot b]=2$. The dislocation is close to edge in character (with Burgers vector $b=1 / 2[1 \bar{l} 0]$ parallel to $g$ ) and is clearly dissociated into partial dislocations of separation - 10nm. Short dislocation dipoles can be seen to the right of the line dislocation. After irradiation with $1 \mathrm{MeV}$ electrons for $1 \mathrm{~min}$ ( $\mathrm{figure} 1(\mathrm{~b})$ ) the dislocation appears constricted. The dipoles appear partially consumed and a number of small white dots (characteristic of small point-defect clusters) has appeared fairly uniformly in the background. 

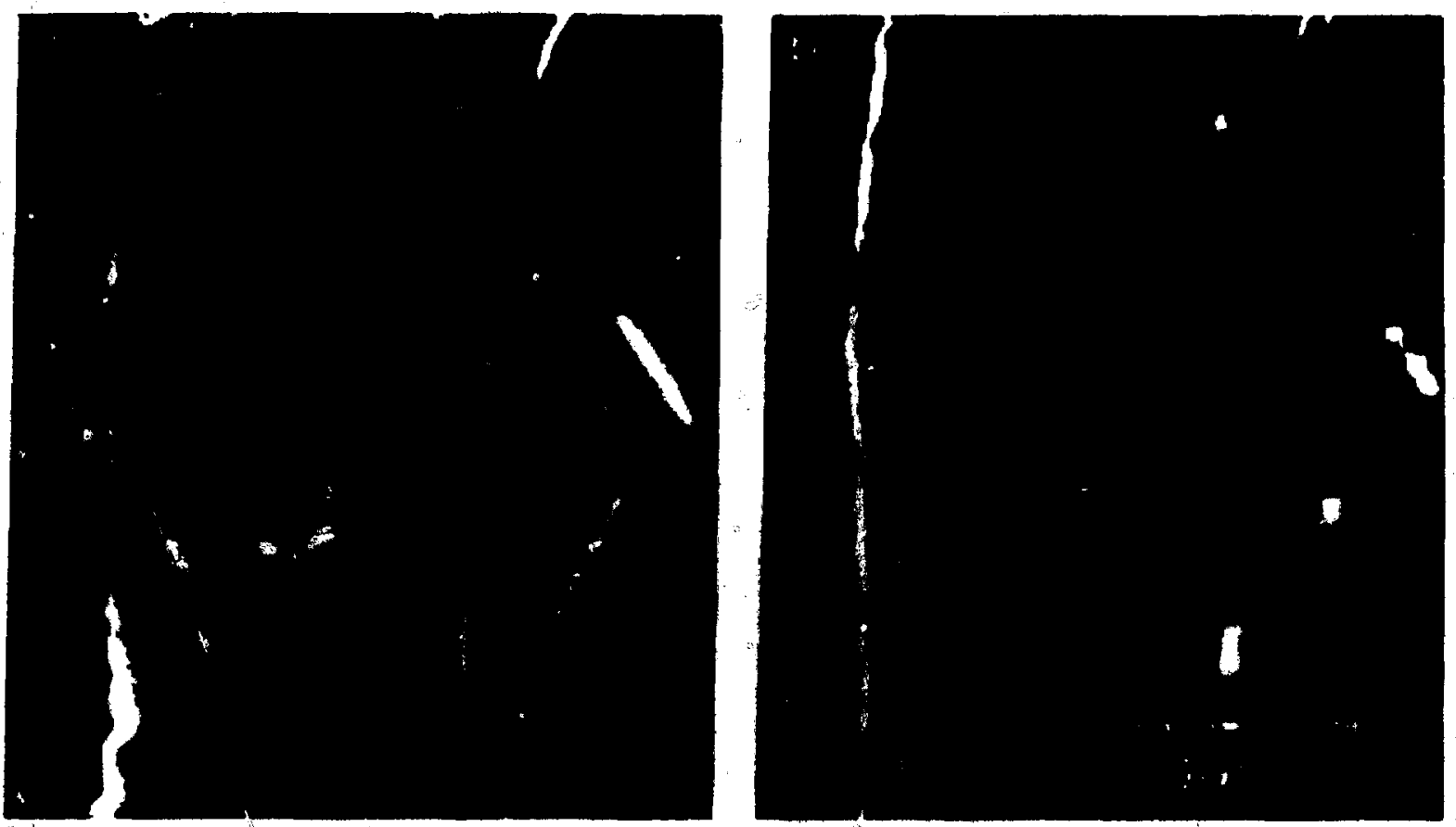

Fig.1: (a) Dissociated dislocation in sllver prior to electron Irradiation, $g=2 \overrightarrow{2} 0, \mid g \cdot p=2 ; \quad$ (b) after $1 \mathrm{MeV}$ electron irradiation for $1 \mathrm{~min}$, $\mathbf{B}=320,|\mathbf{8} \cdot \mathrm{b}| \cdot 2$.

The subsequent development of the damage at the dislocation line is illustrated in the series of micrographs of $f(g y r e: 2(a)-(B)$, which wore all recorded using $8= \pm 11 \overline{1}$. For this reflection $g \cdot b]=0$ and so the dislocation line itself is out of contrast. After 2 mins irradiation ( $f$ gure $2(a)$ ) some small clusters have appeared along the line of the dislocition: inages obtained using other reflections (not shown)" confirm that many ile close to the core. At these early stages of Irradiation most clusters cannot be identifled unambiguously, although arter 5 mins $(f l g u r e s ~ 2(c)$ and $3(a)$ ) some of the larger clusters show the charaoterist10 V-ahaped contrast of small SFT. Later in the irradiation sequence ( $f$ gures $2(d)-(g)$ and $3(b)$ ) many more clusters have formed and most on be recognised as SFr. Note the tendency for clusters to nucleate further and further away from the dislocation line. There is relatively little change in the damage structure between ( 6 ) 7.5 mins and ( $\mathrm{g}$ ) $13 \mathrm{mins}$. After $13 \mathrm{mins}$ electron irradiation the diameter of the cluster-rich zone is $-50 \mathrm{~nm}$.

In a few cases it was possible to correlate SFT at the later stages of irradiation with clusters present at earlier stages, and two examples of these are arrowed in figure 3. The arrowed defect to the left in figure 3 appears to be an example of a SFT which has grown during irradiation. Growth however is slow, particularly for those clusters embedded in the defect cloud, and the dominant effect appears to be the nucleation of new clusters at the periphery of the damage zone. The SFT reach a maximum size of about $8 \mathrm{~nm}$. None was ever observed to convert to a dislocation loop. 
The experiment described above does not give direct Information on the SFT nature. It is however consistent with the hypothesis of interstitial SFT in two respects. First there is evidence that SFT grow during the irradiation. Although the smallest clusters cannot be ldentifled unamblguously, it is possible that these too are small SFT. If the clusters nucleate and grow as SFT then this obviates the need for conversion of Frank loops to SFT by the silcox-Hirsch mechanisa, and so rewoves the objection that operation of this mechanism for Interstitial Frank loops is unlikely. Second, clusters first
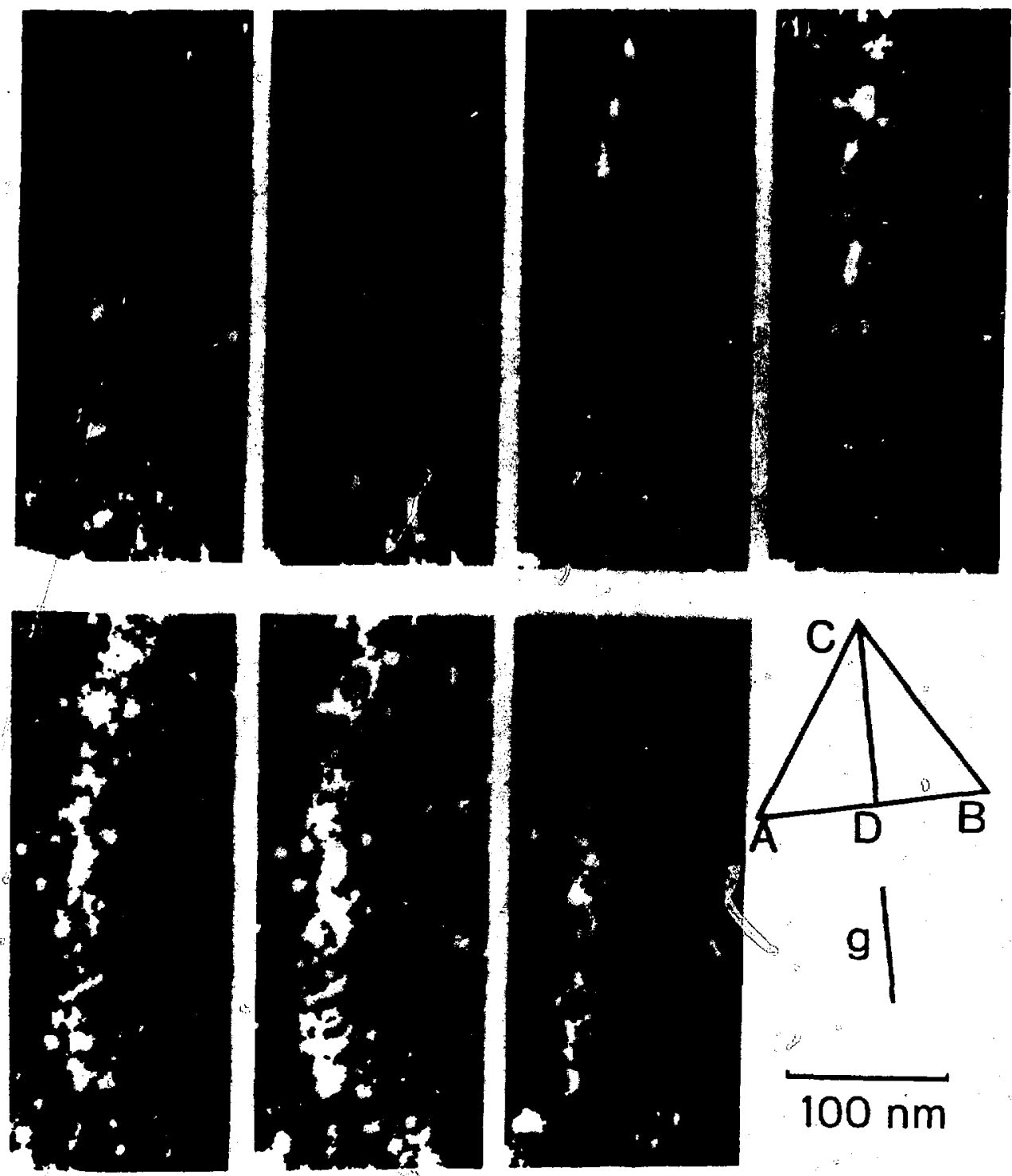

F18.2: Point-defect clusters formed near the dislocation of figure 1. Weak-beam micrographs using $B=11 \overline{1}(a, b, g)$ and $\overline{1} \overline{1}(c-f)$ at the

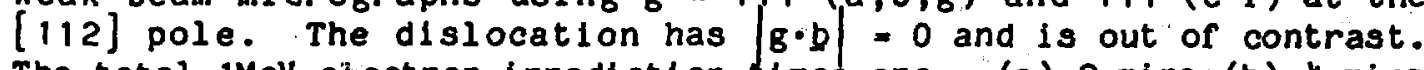
The total $1 \mathrm{MeV}$ eilectron irradiation times are: (a) 2 mins (b) $4 \mathrm{mins}$ (c) $5 \mathrm{mins}$ (d) $6 \mathrm{mins}$ (e) $7.5 \mathrm{mins}$ (f) $9 \mathrm{mins}$ (B) $13 \mathrm{mins}$. 

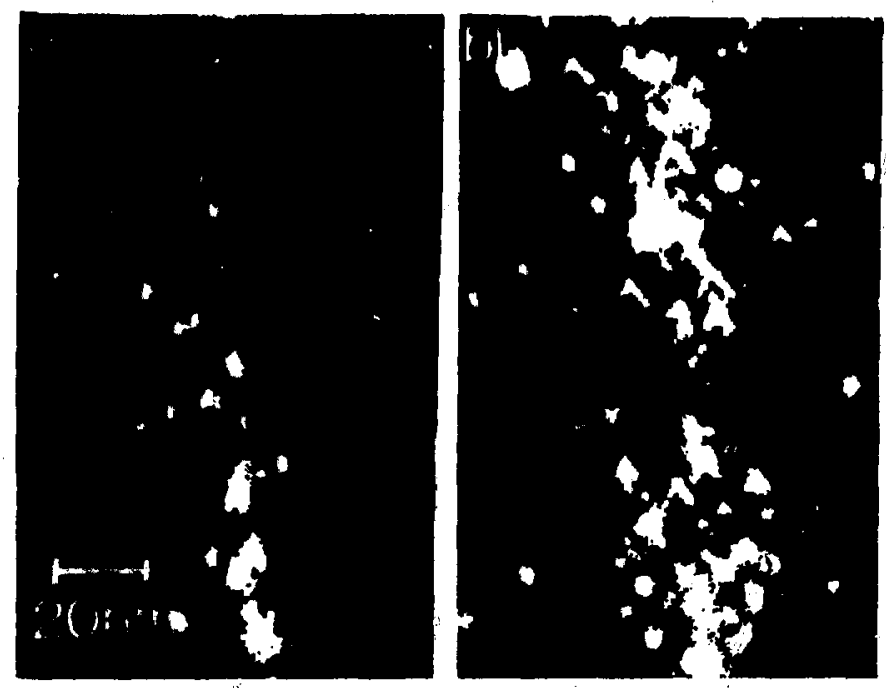

Fig.3: Higher-magnification detalls of figure $2(\mathrm{c})$ and $(\mathrm{g})$. Two clusters present in both inlcrographs are arrowed.

form close to the core or the parent dislocation. This would be as expected if we are observing a variant of the climb mechanisms found in other low stacking-fault energy materials, and cited in the introduction above. On this model we assume that dislocations attract but cannot easily assimilate excess interstitials, which eventually precipltate as interstitial clusters close to the core. In the Cu-alloys and other materials studied it is believed that these clusters are initially Frank loops (see [8]) which unfault to prismatic loops at an early stage, and subsequently interact with the partial dislocations to produce complex configurations. In silver the cluster configuration could be the interstitial SFT, and reactions with the parent dislocation are not expected.

There is however an alternative possibility which is not ruled out by our observations. This is that dislocations act as efficient sinks for interstitials, and so climb by absorbing an excess of interstitials over vacancies owing to the dislocation bias[9]. The relative depletion of interstitials close to the dislocation may lead to favourable conditions for vacancy cluster nucleation, especially in regions of compressional strain. In this case then the SFT would be of vacancy nature. We have no evidence that major climb of line dislocations occurs, but the fact that dislocations constrict at an early stage in the irradiation suggests that this is reasible. Other observations described in the literature also tend to support this viewpoint. Takahashi and Urban[10] have observed small SFT to form in electronirradiated $A g 0.17 \% \mathrm{Cu}$ at the inner peripheries of interstitial loops, 1.e. in the regions of compressional strain. This suggests they are of vacancy nature. Similar observations have been made by Sumida et al[11] in $\mathrm{Cu}$ and Cu3\%A1. Vacancy clusters, of unidentified type, were found to form inside interstitial Frank loops and on the compression side of edge dislocations after irradiations with. 2MV electrons at temperatures from room temperature to $100^{\circ} \mathrm{C}$. These authors also observed major climb motion of dislocations in Cu3FAl in irradiations at $200^{\circ} \mathrm{C}$. Suehiro et al[12] have found small SFT to form in thin foll regions in $\mathrm{Cu}, \mathrm{NI}$ and $\mathrm{Au}$ and at dislocations in $\mathrm{Cu}$ in electron Irradiations at room temperature. We also find that SFT are formed 
In thin regions in silver arter prolonged irradiations. Kiritani[13] has argued that the formation of vacanoy olusters in these cases is a consequence of the presence of efflcient sinks (the surfaces and dislocations) for the moblite interstitials.

Much therefore depends on the rellabllity of the determination of the nature of the SFT by the '2\%D' method[7]. The stereo mecisurements in these exper1ments were carried out blind by a group of our colleagues and the results seemed consistent and reproducible. Recent criticlsm of the '2t/2D' technique by PIskunov[14] does not seem val1d[2]. Gruschel[6] calculated the '2\%D' effect for small SFT and found that the sense of the image shift produced by defocusing depended only on the nature or the SFT and not on other experimental parameters. The magnitude of the expected shlft is however small, a few Angstroms only for the larger tetrahedra ( $5 \mathrm{~nm}$ ) and - $1 \mathrm{~nm}$ for the smallest resolvable tetrahedra ( $-2 \mathrm{~nm}$ ) for the conditions of our experiments. These theoretical image shifts are smaller than the typical estimated image shifts of $2-3 \mathrm{~nm}$ found in our experiments. The statement made in ref.[7] that such Image shifts are 'consistent with the expected value for tetrahedra of this size at this value of defocus' is therefore not correct. For this reason we now view these experiments with some reseivation.

Attempts are now being made to determine the SFT nature using high-resolution structural imaging [15]. These experiments are however extremely difficult because of the small size of the SFT and the requirement for very thin foils. Further experiments are also planned to investigate the three-dimensional disposition of SFT around dislocation lines and large dislocation loops and to study the climb motion of dislocations and for these experiments the Argonne HVEM seems ideally suited.

\section{FEFERENCES}

[1] Cherns, D., Hirsch, P.B. and Saka, H., 1980, Proc.Roy.Soc. A371, 213.

2. Hardy, G.J. and Jenkins, M.L., 1986, submitted to Phil.Mag. A

3. Décamps, B., Cherns, B. and Condat, M., 1983, Phil.Mag. A48, 123.

4] Ourmazd, A., Cherns, D. and Hirsch, P.B., 1981, Inst.Phys.Cone.Ser. No.60, 39 .

[5] Cherns, D. and Feuillet, G., 1985, Phil.Mag. A51, 661.

6. Gruschel, W., 1979, Dr.rer.nat. Thesis, University of Stuttgart.

7. Hardy, G.J. and Jenkins, M.L., 1985, Phil.Mag. A52, L19.

[8] Cherns, D., 1984, D1slocations 1984, Proc.Int.Colloq., Aussois, France, ed. P. Veyssier, L. Kubin and J. Castaing (CNRS Paris). p215.

[9] Heald, P.T., 1975, Phil.Mag., 31, 551.

10]. Takahashi, H. and Urban, K., 1981, phys.stat.sol. (a) 67, 347 .

11. Sumida, N., Fujita, K., Takamoto, K. and Sawada, A., as 12, p882.

[12] Suehiro, M., Yoshida, N. and Kiritani, M., 1982, Point defects and defect interactionsin metals, Proc. of Int. Conf., Kyoto ed. J Takamura, $M$ Doyama and M Kiritani (North Holland, Amsterdam) p795.

[13] Kiritani, M., 1975, Proc.Int.Conf. on Fundamental Aspects or Radiation Damage in Metals, Gatlinburg, USA, ed M.T. Roblnson and F.W. Young Jr, NSF CONF-751006-P2, p695.

[14] Piskunov, D.I., 1985, Sov. Phys.Solid State 27, 2125.

[15] Coene, H., Bender, H. and Amelinckx, S., 19 $\overline{85}$, Phll.Mag. A52, 369. 